\title{
Investigation of zero energy house design: Principle concepts opportunities and challenges
}

\author{
Hasan Ikbal Altintas ${ }^{1}$ \\ ${ }^{1}$ International University of Sarajevo, Bosnia
}

*Corresponding author: hasan.ts61.43@gmail.com

(c) The Author(s)

2019.

Published by ARDA.

\begin{abstract}
This research paper examines the concept of a zero-energy house in detail. A lot of literature was revised to define the zero-energy house and identify its application worldwide. Furthermore, several key trends triggered by zero energy houses were reviewed and mentioned to indicate the importance of this hot topic of the 21 st century. Besides, issues and challenges facing this concept were discussed. Technological, economical, institutional barriers are only a few of the many barriers discussed in this research paper that have huge impacts on the concept of zero-energy houses. Later on, two different studies conducted in distinct locations were examined. The first study used TRNSYS building software along with the lumped capacitance building model to investigate the thermal performance of net-zero energy houses for the sub-zero temperature areas. It aimed at creating a net-zero cost-effective energy house for the areas with sub-zero weather conditions. The findings have shown that there is a good tendency for the construction of zero-energy houses. The second study aimed to design a zero-energy house in Brisbane, Australia by using the EnergyPlus 8.1 building simulation software. Energy performance, potential energy savings, and the financial feasibility of zero-energy houses were analyzed. After a thorough investigation, results have shown that designing a zero-energy house in Brisbane sounds like an attractive and possible choice. From the financial aspect, it seems that building a zero-energy house would definitely pay off.
\end{abstract}

Keywords: First keyword, Second keyword, Third keyword, Fourth keyword, Fifth keyword

\section{Introduction}

This research paper aims to investigate the concept and usage of zero energy houses. Their application from different countries will be analyzed in details to see their impact on the environment and to identify the way they impact building physics. First of all, it is important to see what are zero energy houses, how are they defined, what is their purpose and in what way they contribute to the health of the environment. Furthermore, this paper will rely on secondary information and the studies already conducted to provide better insights and methods widely applied related to the zero energy houses. Although many people think that the phenomenon of zero energy houses is quite new, evidences indicate differently. According to the researches, the term 'zero energy house' was used in articles during the late seventies and early eighties because that was the time when oil crisis affected the world forcing the scientists to start thinking of the problems related to fossil fuels and the use of the energy [1]. Despite that, the importance was not given to zero energy houses until recently when different kind of environmental disasters hit the world, and when the environmental sustainability started

This work is licensed under a Creative Commons Attribution License (https://creativecommons.org/licenses/by/4.0/) that allows others to share and adapt the material for any purpose (even commercially), in any medium with an acknowledgement of the work's authorship and initial publication in this journal. 
being placed amongst the highest concerns to think about. It is really significant to look after the solutions which will less harm our environment and which will improve environmental conditions in general. One such solution can be found in the zero-energy house. Zero energy houses do not differ from other typical houses in any aspect. But what other houses do not have and zero energy house has is the fact that it is energy efficient and that it is able to produce as much renewable energy as it consumes over a certain period of time. Besides being well insulated, the owners of zero energy houses live in the home which is carbon-free, affordable, and at the same time much more comfortable and healthier to live in. In a time when global climate change presents a real issue, zero energy houses each day become more and more important in the construction industry [2]. Zero energy houses can be made in different sizes and shapes without any problems. Also, they can be built in various climatic regions from the dry and warm climate to the cold climate. When speaking of zero energy houses, it is important to mention that they mostly use solar panels combined with modern and advanced designs of building system. Another important aspect that should be considered is the financial feasibility provided by these houses.

\section{Zero energy house concept}

As described by Yuanming Kwan and Lisa Guan, a zero energy house is a typical house with net zero energy consumption on annual basis which further indicates that the amount of the consumed energy equals the amount of renewable energy produced in a year [2]. They also explained that in case when no renewable energy is available, the power grid will supply the house with the electricity which will be returned back to the grid when there is an excess power generated out of the renewable energy supply [2]. Besides zero energy house concept, other related concepts are introduced as well. "Near zero" and "net zero ready" house concepts are additionally being produced. "Near zero" perceives that when a house's purchased energy is low and is near to the net zero target. "Net zero ready" perceives when the house's infrastructure and building envelope are created to encourage the expansion of appropriately estimated solar energy technologies post development. The choice to include solar technologies could be, for instance, as solar based costs decay, as fossil fuels costs rise, and as worries with fossil fuel resource depletion and environmental degradation continue to rise [3]. The net zero energy objective is accomplished by utilizing a mix of technologies that diminish house energy necessities and use on-site renewable energy systems. Particularly, a net zero energy strategy would refer to:

1. decreases domestic electricity consumption through energy efficient appliances and lighting;

2. decreases household water heating necessities through water productive apparatuses;

3. decreases space heating and cooling energy utilizing an energy efficient building envelope;

4. utilizes suitable site-based sustainable energy systems to supply heat and electricity [3].

Studies conducted on the topic of zero energy houses have found that the use of renewable energy mostly incorporates the solar photovoltaic technology, solar thermal technology, ground source heat pump, and so forth [4]. Shihao Zhang et al. stated that the photovoltaic/thermal (PVT) collector represents an efficient solar energy solution which immediately converts the solar energy into the heat and electricity [4]. We can notice that the thermal performance within the zero-energy house is deeply considered and analyzed in order to find appropriate solutions for optimizing the energy performance. Thermal performance of houses and buildings is one of the main concepts of building physics and it plays important role in the zero energy houses. It seems that the good way of using the renewable energy together with low-level thermal energy would be reflected through the integration of heating, ventilation, and air conditioning system (HVAC) with the photovoltaic system (PV) system [4]. Going further, we again encounter the significant aspects of building physics such as HVAC system implemented and taken into account within zero energy houses. Zero energy houses need to create their own energy on site to meet their electricity and heating or cooling needs. Different microgeneration technologies might be utilized to give heat and electricity to the building, including:

- solar: solar hot water, photovoltaics (PV),

- wind: wind turbines,

- biomass: radiators/stoves, boilers, and network heating schemes,

- combined heat and power (CHP) and smaller scale CHP for use with the accompanying fuels: natural gas biomass sewerage gas and different biogases, 
- network heating, including using waste heat from substantial scale power generation,

- heat pumps: Air source (ASHPs) and ground source (GSHP), and geothermal heating systems,

- water: Small scale hydro control,

- other e.g. energy components utilizing hydrogen produced from any of the above 'sustainable' sources [5].

As indicated in the researches, the increase of global energy consumption is forecasted to rise by almost $56 \%$ between 2010 and 2040, and only residential sector is expected to pose increase of 1.5\% on annual basis [2]. These forecasts present a serious concern for all countries that care about their usage of energy and how well it is used. Many countries have already employed relevant departments and agencies to work on such issues. For instance, Australian Sustainable Built Environment Council appointed a group of people to work on the goal of accomplishing a zero-energy performance and zero carbon for the existing and future homes by 2020 [2].

The majority of people may not be familiar with the negative effects of carbon dioxide which is emitted into the atmosphere as a consequence of the fossil fuels combustion. However, people should educate themselves more in order to realize the harsh and serious consequences that use of fossil energy has on the world reserves of non-renewable energy sources [6]. The UK government has already taken some measures against carbon emissions and proposed a policy named Code for Sustainable Homes in which it outlined the aim for new houses to be zero carbon by 2016 [7]. This policy is shown on the table 1 below.

Table 1. Code Levels for Mandatory Minimum Standards in CO2 Emissions [4]

\section{Code $\quad$ Minimum Percentage Improvement in Dwelling Emission Rate over Target Emission}

Level Rate

\begin{tabular}{l|l}
\hline Level 1 & $0 \%$ (Compliance with Part L 2010 only is required) \\
Level 2 & $0 \%$ (Compliance with Part L 2010 only is required) \\
Level 3 & $0 \%$ (Compliance with Part L 2010 only is required) \\
Level 4 & $25 \%$ \\
Level 5 & $100 \%$ \\
Level 6 & Net Zero CO2 Emissions
\end{tabular}

Elena Perlova et al. indicate that the attention should be devoted to the housing stock which consumes approximately $30-40 \%$ of all energy in order to reduce fuel consumption and energy consumption [6]. Researchers from Russia proposed how it would be enough work on the increment of the regulatory requirements for the insulation levels, to install systems heat recovery of exhaust air and a more effective and efficient heating system accompanied by the improvement of the degree of building automation when setting the parameters of the coolant to enter the home or building [6].

Studies conducted already expressed the concern about the way and speed with which the energy is consumed. In addition, if we consider the fact that the stocks of non-renewable energy are almost finite, it implies that the main characteristics of homes and buildings in the future will be low energy consumption almost close to zero. Aware of the threats and risks, countries started establishing the standards for energy use and consumption.

Many surveys have been conducted while studying the nZEB, and their major concern was the optimization of building envelope, the improvement of the electromechanical systems together with the introduction of renewable energy sources [8].

\subsection{Key trends behind the zero energy houses}

While there is no hard information on the development of net-zero energy homes, there are information that demonstrate an expansion in the more extensive area of energy effective homebuilding. The share of the single-family home construction market in Portland, USA devoted to green development developed from $8 \%$ in 2008 to 17\% in 2011, as indicated by a report distributed by McGraw-Hill Construction in 2013 [9]. The report evaluates that green home development - characterized as naturally dependable and energy productive, 
yet not really net-zero - will develop its piece of the overall industry to between $29 \%$ and $38 \%$ by 2016 [9]. The numbers recommend that net-zero energy homes, as a subset of the green homebuilding market, are pushing toward more extensive adoption.

In spite of the fact that there is no association or state office that tracks the quantity of net-zero energy homes built in Maine, Portland every year, there is developing episodic proof that net-zero energy homes are growing [9]. Growing expenses for fossil fuel heat, the ongoing persevering winter and the falling expenses of renewable energy technology are prodding interest.

"Year over year we're seeing steady growth in new development of net-zero homes," said Phil Coupe, cofounder of Revision Energy in Portland [9]. "What's more, the greater part of those undertakings become obvious on the grounds that because they include solar electricity into the development designs" [9].

The government of United States has focused on grasping net-zero energy development. President Obama issued an official request in 2009 that requires all new government structures to be planned as net-zero by 2030.

Homes assembled today without energy efficient designs will be outdated inside the decade, says Phil Kaplan, an originator of Kaplan Thompson Architects, which has built 40 net-zero energy homes since it was established in 2004, however not all in Maine, Portland [9].

It is obvious that each and every country seeks ways of improving the energy performance of already existing residential stock. The European Union also set some targets regarding the reduction of greenhouse gas emissions. More precisely, they aim at improving the energy efficiency by $20 \%$ as well as to increase the volume of European energy consumption coming from renewable resources by $20 \%$ [8]. For European Union to achieve its targets and goals by 2020, they emphasize the importance of nearly Zero Energy Building or so called 'nZEB' [8].

\section{Issues and challenges}

Although the zero-energy house is an ultimate goal to achieve for each country, there are still some issues and barriers that they have to face while wanting to build zero energy houses. Various barriers including technological, economical, regulatory, institutional barriers, and so forth complicate the construction of zero energy houses. Many different barriers will be explained in this part as some of the greatest issues related to this topic.

\subsection{Technological barriers}

Technological barriers represent one of the major issues that construction of zero energy houses face. Technological barriers occur because of various distinctive aspects influencing zero energy house building. One is the incorporation of unconventional technologies in such structures, from solar panels to modern ventilation systems [10]. Another is the requesting determinations for ordinary building segments, for example, insulation. Third, with the end goal to guarantee that the building executes obviously, it is considerably more critical than with ordinary structures that development is done as indicated and to exclusive requirements.

All through the construction sector, there is as yet an absence of the expertise and skills that are required with the end goal to manage the three prerequisites specified above, and additionally vulnerability about how new technologies perform [10]. Advancement on development forms is expected to discover dependable methodologies that will survive these technological barriers. One answer for these issues is the utilization of offsite construction, in any case, this in itself is a method that numerous developers are new to and that requires a high level of coordination between the different parties included, which can demonstrate testing [10].

Until now many simulations have been conducted by using the technological devices and they demonstrated that the proposed nearly zero energy buildings (nZEB) standards are achievable and reachable with already existing innovations. From the many simulations performed, the vast majority of the cases indicate the need for remunerating estimates, for example, green power or on location renewable power (i.e. photovoltaic). Every single electric arrangement (heat pumps) appear to be among the most reasonable arrangements, primarily due to the continuous and expected decarbonization of the power division and due to on-site 
renewable energy. District heating systems have an incredible potential also however just under the condition of higher offers of sustainable power source (positively higher than half) than accepted in the recreations.

Further improvements towards very effective thermal insulation materials and windows, and in addition of heating, cooling and ventilation advances, will expand the accessible alternatives and will push the nZEB limits towards higher exhibitions and conceivably more moderate expenses. But for accomplishing legitimate dimensions of market organization for energy effectiveness advances it is important to up-scale the real dimensions and to encourage the market entrance of promising new advances.

\subsection{Financial and economic barriers}

Economic and financial barriers can be partitioned into two major classes - high expenses of construction, and the trouble of acquiring financing. An absence of assets as well as failure to anchor back on worthy terms is by and large one of the most referred to boundaries to putting resources into energy effectiveness measures, such as in zero energy houses [10]. This is more because of the absence of mindfulness or absence of enthusiasm in favor of lenders instead of the absence of assets [10]. Another critical barrier recognized is the long payback time for interest in energy efficiency measures. Volume impacts could decrease unit manufacturing costs for technologies, yet this is hard to accomplish because of the very divided nature of the building stock [10]. The view of the significance of the cost barrier fluctuates altogether between diverse onscreen characters, with the individuals who are more acquainted with very energy effective structures frequently considering it to be to a less barrier than those with little involvement with this sub-division. It has been accounted for that there is, truth be told, a learning-by-doing impact - so the development of exceptionally energy efficient structures will be more affordable for those who have more involvement with it.

\subsection{Legislative barriers}

At present the overwhelming administrative barrier is the absence of arrangement and lawful structures. The accompanying administrative and authoritative barriers have been recognized: It has been claimed that the major regulatory barrier was the lack of clearly specified standards and specifications related to the zero energy houses [10]. Furthermore, there is a broad uncertainty with regards to the degree and technique by which renewable energy should be included into the building plan [10]. Sometimes legislation unexpectedly frames an obstruction, when laws that were made in various occasions and for various purposes forestall advancement.

\subsection{Knowledge and institutional barriers}

Skills, awareness, knowledge and abilities have been identified as missing factors in many studies conducted [10]. It has been indicated that building professionals were lacking the relevant knowledge and understanding of effectiveness of specific technologies [10].

On the other hand, what is more devastating is the fact that the construction industry itself is too conservative and it reflects throughout the resistance of developers and constructors to many changes that will be necessary to do in order to build zero energy houses at a large scale [10].

\section{Methods}

This part of the paper will examine some of the methodologies, that is computer software, applied on zero energy houses by different people living in different countries and under different weather and climate conditions. The reason I am mentioning this is to see in which ways zero energy houses could be achieved and used.

\subsection{TRNSYS Software and lumped capacitance building model}

First case study that will be considered analyzed the thermal performance of net zero energy home for subzero temperature areas [11]. The main goal of this study was to create a net-zero cost-effective energy house for many locations which have sub-zero weather conditions. The researchers included available renewable energy resources to generate the energy including the wind and solar energy. In order to evaluate the performance of the system, seven distinct locations with different weather environments were chosen. Those seven locations included Barcelona (Spain), Carolina (USA), Karachi (Pakistan), Lahore (Pakistan), Quetta (Pakistan), Sydney (Australia), and Toronto (Canada) [11]. More detailed information regarding the selected areas are provided in the table 2 . 
Table 2. Details about used locations in the study [7]

\begin{tabular}{ccccc} 
Sr. & City & Country & Latitude angle & Longitude angle \\
\hline $\mathbf{1}$ & Barcelona & Spain & $41.3851^{\circ} \mathrm{N}$ & $2.1734^{\circ} \mathrm{E}$ \\
\hline $\mathbf{2}$ & Carolina & USA & $35.7596^{\circ} \mathrm{N}$ & $79.0193^{\circ} \mathrm{W}$ \\
\hline $\mathbf{3}$ & Karachi & Pakistan & $24.8607^{\circ} \mathrm{N}$ & $67.0011^{\circ} \mathrm{W}$ \\
\hline $\mathbf{4}$ & Lahore & Pakistan & $31.5204^{\circ} \mathrm{N}$ & $74.3587^{\circ} \mathrm{W}$ \\
\hline $\mathbf{5}$ & Quetta & Pakistan & $30.1798^{\circ} \mathrm{N}$ & $66.9750^{\circ} \mathrm{W}$ \\
\hline $\mathbf{6}$ & Sydney & Australia & $33.8688^{\circ} \mathrm{S}$ & $151.2093^{\circ} \mathrm{E}$ \\
\hline $\mathbf{7}$ & Toronto & Canada & $43.6532^{\circ} \mathrm{N}$ & $79.3832^{\circ} \mathrm{W}$
\end{tabular}

This research was done by the usage of TRNSYS software in order to analyze the energy efficiency and performance data for different home designs [11]. In order to achieve the maximum efficiency from the onsite renewable resources, the comparison between energy performance and optimizations are done, and the design of the building is created.

Designing a net-zero energy home requires a lot of expertise and attention since disturbing situations are not avoidable. The main goal is to decrease the demand for energy of the building by 50\% [11]. TRNSYS model used is illustrated on the figure 1 and it exhibits how the process go.

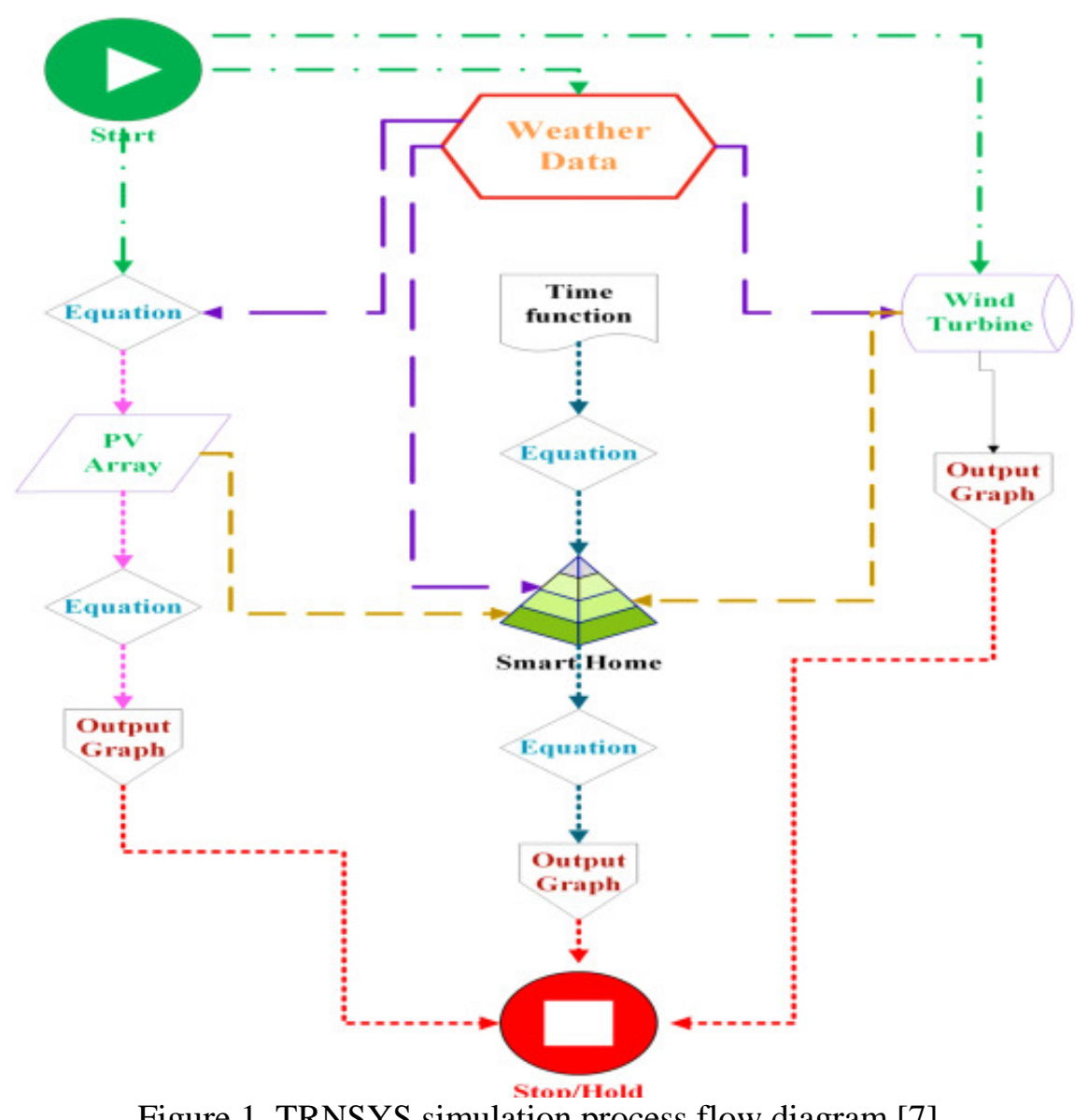

Figure 1. TRNSYS simulation process flow diagram [7]

TRNSYS model, more precisely a computer tool, provides valid methods for analyzing the load of the building, on-site generation and links between the mixture of possible energy options that could be used in order to design a net-zero energy house [11]. The lumped capacitance building model is used later on and it serves as a core of the entire model. This model takes into consideration the various factors such as ambient temperature, humidity ratio of ventilation air, mass flow rate, energy gains from lights and people [11]. 
Many other factors are accounted as well including the building capacitance, building loss coefficient, density of building air, heat, temperature, humidity ratio and so forth [11]. The figure 2 illustrates all the components involved in the TRNSYS model.

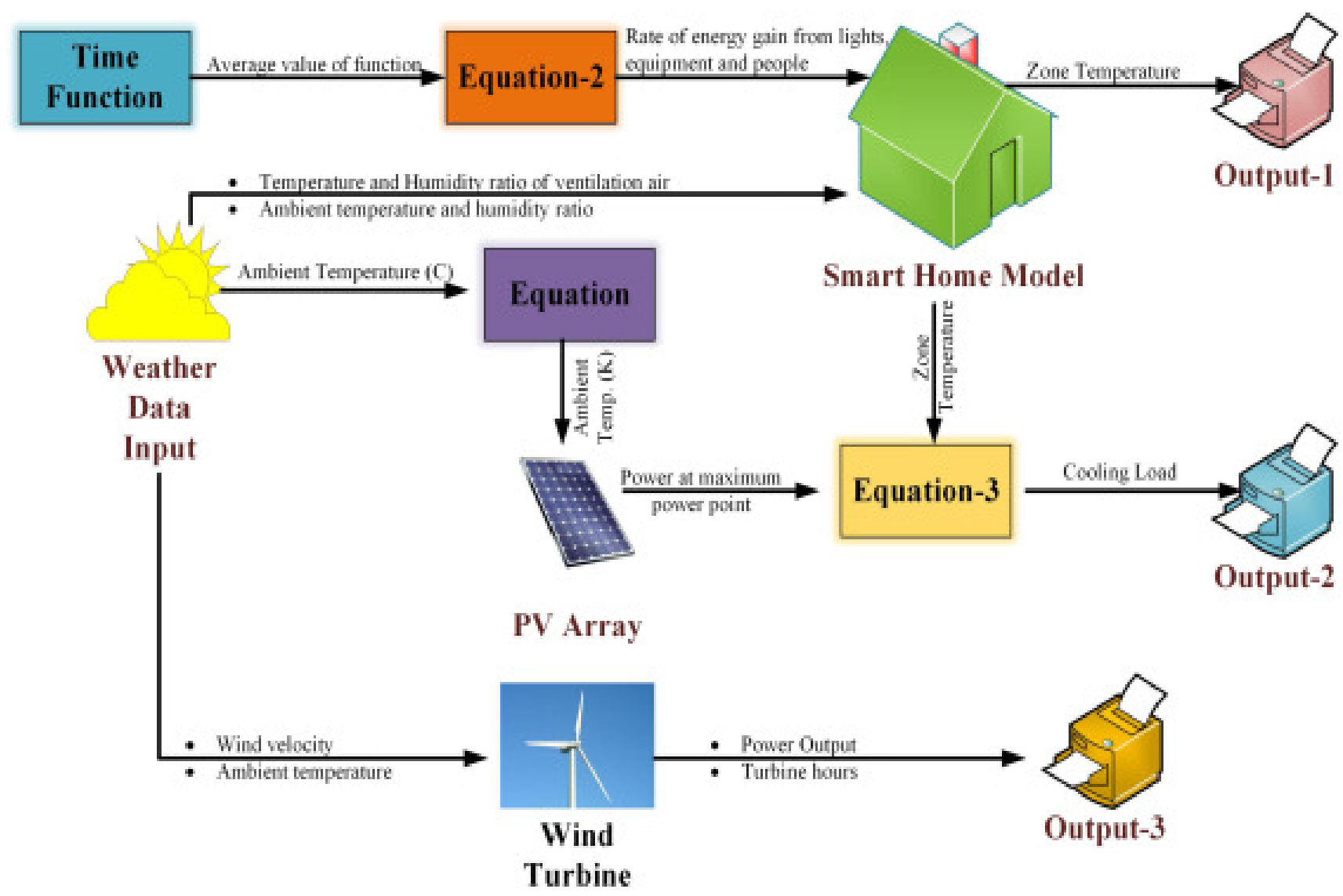

Figure 2. TRNSYS model's components [7]

Last but not least, it is important to mention that time frame is also defined before the simulation was done. So, January was selected to represent the winter while July was the representative of summer weather conditions.

\subsection{EnergyPlus 8.1 building simulation software}

Another interesting research related to the zero-energy house is the one done by Yuanming Kwan and Lisa Guan. They wanted to analyze the energy performance, potential energy savings and the financial feasibility of zero energy houses by designing it based on the typical house in Brisbane [2]. Thanks to the computer simulation, the energy performance of the house is examined under the climate conditions of Brisbane. Already mentioned, this study used building simulation software known as EnergyPlus 8.1 which included the weather conditions of study location, base case modelling and case validation [2].

The data used for the climate conditions in Brisbane was secondary data based on the Typical Meteorological Year weather profile dataset. EnergyPlus building software is developed by the U.S. Department of Energy, and it involves the characteristics of DOE-2 and BLAST [2]. It can work on modeling heating, cooling, ventilation, lighting as well as other energy flows [2]. According to its advanced features, it seems that this building software is a great software for modeling the energy performance of the zero energy houses.

The zero-energy house designed for the purposes of this study was a 5-star energy, modern, single-storey veneer house made of brick. The plan of the house and its 3D picture are provided in the next two figures. 


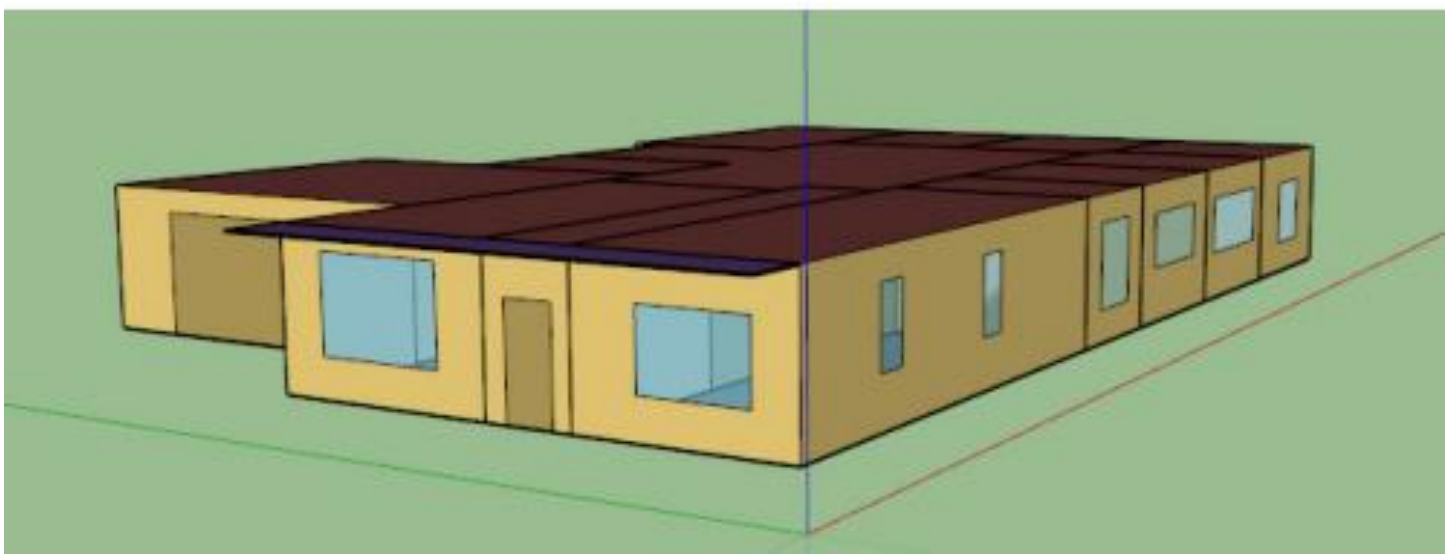

Figure 3. Zero energy house designed in Google SketchUp [2]

As it could be noticed from the floor plan, zero energy house is consisted of four bedrooms, living room, two bathrooms, a kids' TV room, a kitchen area, a rumpus room, a garage, a laundry and an entrance walkway.

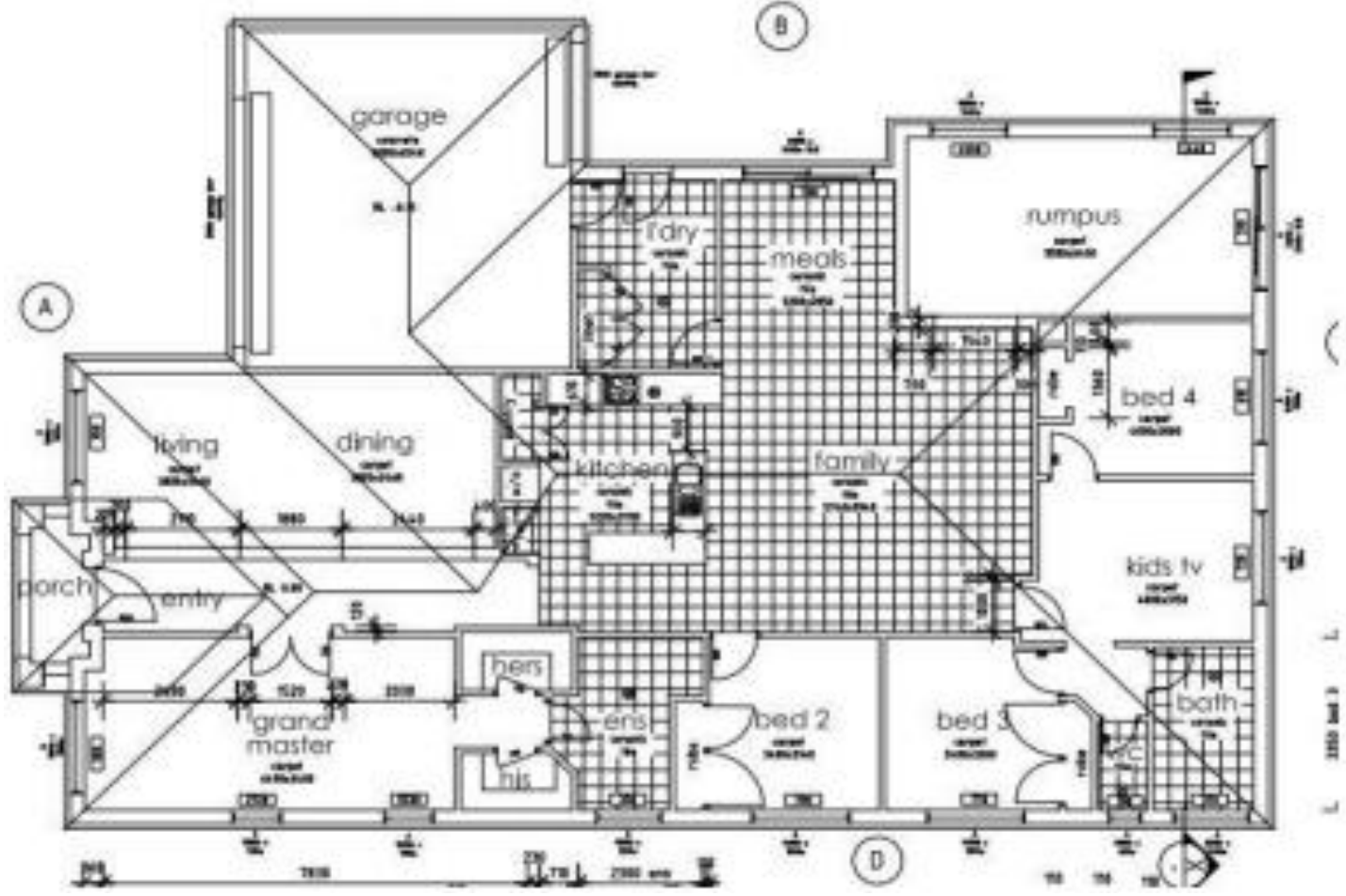

Figure 4. Floor plan of a designed zero energy house [2]

The construction specifications of the house model are clearly defined as well as it can be seen in the table 3 .

Table 3. Construction specifications of the zero-energy house model [2]

\section{Construction Type}

External walls
Materials

$100 \mathrm{~mm}$ brick, $50 \mathrm{~mm}$ insulation board, wall air space and $9.5 \mathrm{~mm}$ plaster board.

External walls (garage) $100 \mathrm{~mm}$ brick, wall air space and $9.5 \mathrm{~mm}$ plaster board.

Internal walls Double layer $9.5 \mathrm{~mm}$ plaster board and wall air space

External door (front) $50 \mathrm{~mm}$ wood.

External door (garage) $\quad 50 \mathrm{~mm} \mathrm{steel} \mathrm{(metal).}$ 


\begin{tabular}{ll} 
Construction Type & Materials \\
\hline External door (laundry) & $50 \mathrm{~mm}$ softwood. \\
\hline Internal doors & $25 \mathrm{~mm}$ wood. \\
\hline Windows & $3 \mathrm{~mm}$ green glass (single glaze), air $13 \mathrm{~mm}$ and $3 \mathrm{~mm}$ clear glass. \\
\hline Floor (carpet) & Carpet and $100 \mathrm{~mm}$ lightweight concrete. \\
\hline Floor (tiles) & Acoustic tile and $100 \mathrm{~mm}$ lightweight concrete. \\
\hline Ceiling & $\begin{array}{l}100 \mathrm{~mm} \text { concrete, ceiling air space, } 154 \mathrm{~mm} \text { batts insulation and } 13 \\
\mathrm{~mm} \text { plasterboard. }\end{array}$
\end{tabular}

Furthermore, the lighting levels were specified in accordance with BCA Lighting Benchmarks, selecting the $2.77 \mathrm{~W} / \mathrm{m} 2$ as a lighting density for the rooms including the bathrooms, kitchen, and living area [2].

Since the researchers of this study relied on secondary data which implied that the residential homes in Brisbane typically use heat pump air conditioning system, they used heat pump as a representative of the air conditioning system of the zero energy house [2]. A cooling set point was settled at 25.5 Celsius degrees while the heating set point was settled at 21 Celsius degrees [2]. The gas storage hot water heating system with a tank of $0.4 \mathrm{~m} 3$ were modelled during the design of the zero-energy house model [2]. Once when all necessary parameters were included into the model, the energy performance of the house was measured and evaluated.

\section{Results and discussions}

\subsection{Results of TRNSYS Software}

Related to the first case study from 3.1. section which was applied in seven different locations, it has been found out that the simulation indicated at the good possibility and likelihood for the installation of the Photovoltaic system [11]. Furthermore, the city of Pakistan expressed a large tendency and potential for the installation of solar systems. During the summer period, the maximum of $1400 \mathrm{~W}$ was generated while the Sydney expressed $1400 \mathrm{~W}$ during the January [11]. Barcelona exhibited lower value of generated power during the winter season because of the lower insolation offered [11].

Besides, the results of the study related to the wind energy conversion system indicated that the places with high wind concentration have chances of the installation of wind turbines which was especially case in Pakistan and Sydney as having the highest value of wind generation [11]. On the other hand, the Canada, United states and the European countries expressed lower wind velocities which means that their energy generation by the wind has lower values as well [11]. Data indicated that Sydney has the highest value of wind capacity of $0.7 \mathrm{MW}$, followed by Karachi having $0.4 \mathrm{MW}$ wind capacity. Below are the values of wind power generation in the figure 8 , and illustrated graphically on the chart through the figure 9.

Table 4: Power generation by wind turbine [11]

\begin{tabular}{ccccc} 
S. NO. & CITY & \multicolumn{3}{c}{ PEAK WIND POWER GENERATION (MW) } \\
\hline & & January week & July week & Yearly \\
$\mathbf{1}$ & Barcelona & 0.36 & 2 & 2.1 \\
$\mathbf{2}$ & Carolina & 0.2 & 1.2 & 1.5 \\
$\mathbf{3}$ & Karachi & 0.4 & 1.85 & 1.9 \\
$\mathbf{4}$ & Lahore & 0.18 & 1.3 & 1.5 \\
$\mathbf{5}$ & Quetta & 0.3 & 1.3 & 1.8 \\
$\mathbf{6}$ & Sydney & 0.7 & 1.7 & 2.0 \\
$\mathbf{7}$ & Toronto & 0.6 & 1.9 & 1.95 \\
\end{tabular}




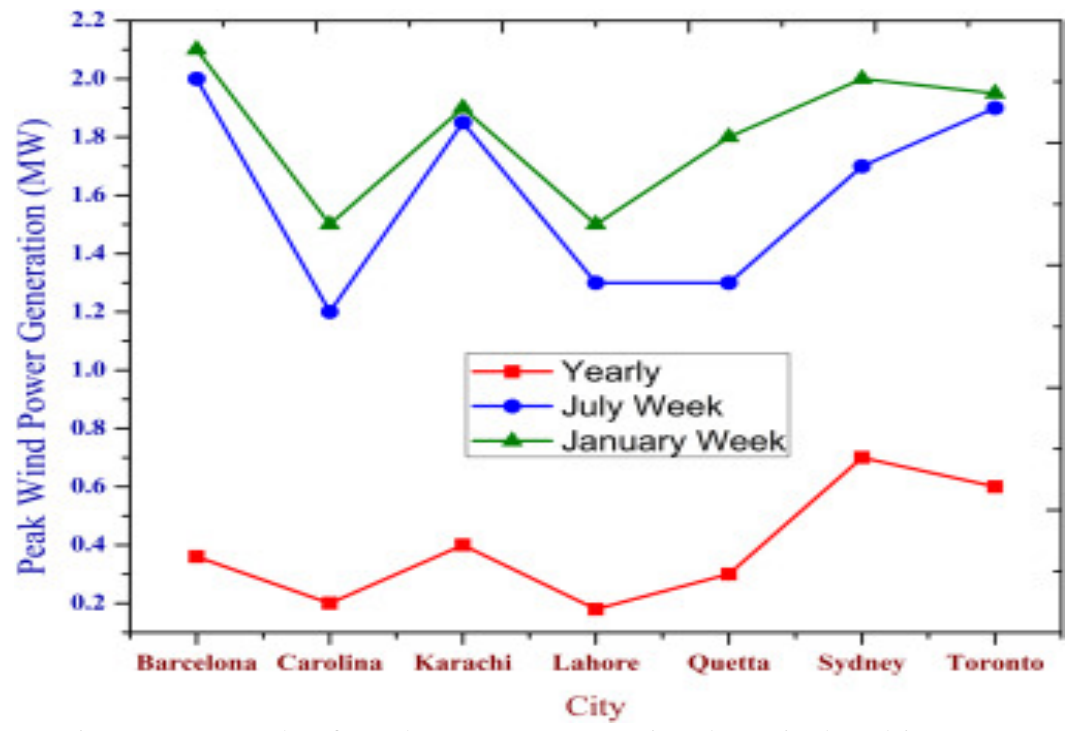

Figure 5. Graph of peak power generation by wind turbine [11]

\subsection{Results of lumped capacitance building model}

Zone temperature was the main parameter to be studied during the examination of the thermal loads along with the demand within the building. For the sake of this research study, only one zone structure which is subjected to the internal gains was simulated to accomplish the net zero [11]. According to this study, the zone temperature is defined as the temperature exiting the hot side of the heat exchanger and returning to the heat source [11].

Zone temperature was calculated in the following way:

Where Tout $=$ temperature outlet

$$
\text { Tout }=\text { Tir }-Q h x / m d o t / C p
$$

Tin $=$ inlet temperature to load heat exchanger

$\mathrm{Qhx}=$ heat exchanger heat transfer

Mdot $=$ pump flow rate

$\mathrm{Cp}=$ source fluid specific heat [11].

Furthermore, the simulation results regarding the areas with cold climate exhibited the need for fewer amount of energy for building to heat up and internal comfort of the zones [11]. On the other side, the highest value for hot climate area was 62 Celsius degrees, while the 30 Celsius degrees was recorded in Toronto during the winter time (January) [11].

\subsection{Results of EnergyPlus 8.1 building software}

Moving to the second case regarding the design of zero energy house in Brisbane, interesting results were recorded. Firstly, the results of the average heat loss and heat gains through the building envelope will be showed in the next two charts.
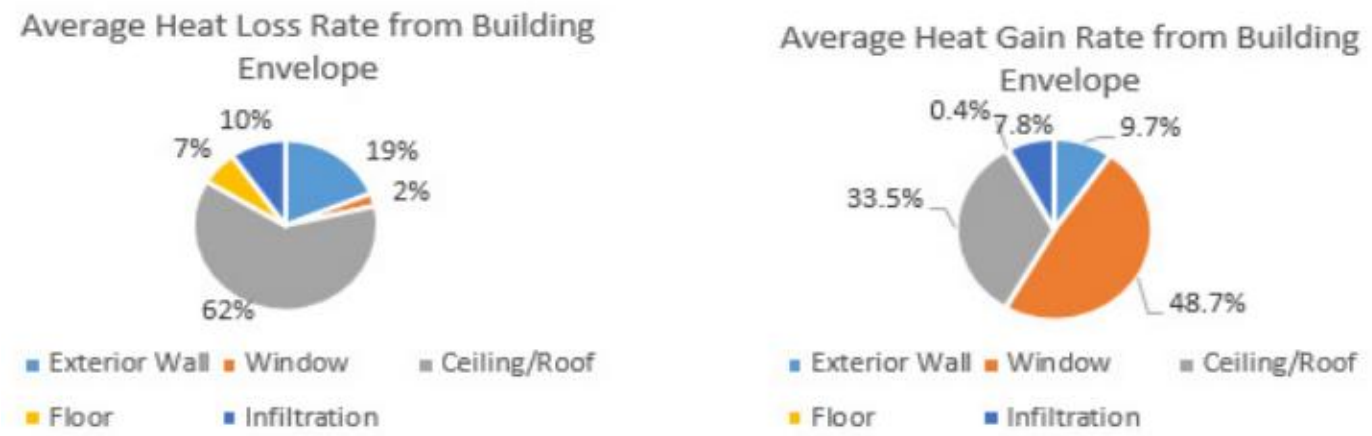

Figure 6. Average heat loss and gain [2] 
Then, it was found that the cooling load was mostly affected by the solar gain (44\%), building envelope (39\%), and internal load (10\%) [2]. Furthermore, various factors such as building construction, alternative hot water system, HVAC system and energy efficiencies of appliances and lighting were included to recognize potential strategies for the house energy consumption. The best design of building envelope should have increased insulation for ceiling and external walls, shaded exterior window and reflective window glaze, together with reflective roof [2]. All this would contribute to the reduction of energy consumption.

Besides, changes must be applied in lighting and appliances in order to make them energy efficient. Also, the usage of hot water collectors including the hot water, heating and cooling, would reduce the energy consumption by the domestic hot water as well as HVAC system [2]. If all these modifications are applied, then the energy consumption is definitely reduced by $66 \%$. Considering the fact that Brisbane is a sunny place having 4.2 hour peak sun on average, facilitates the use of solar energy in order to achieve the energy balance. By using the silicone photovoltaic panel system, it is possible to compensate the annual energy demand of the house [2].

Figure 11 clearly indicates the results of the simulation which shows that house achieves zero energy performance by generating more energy than the energy spent each month [2].

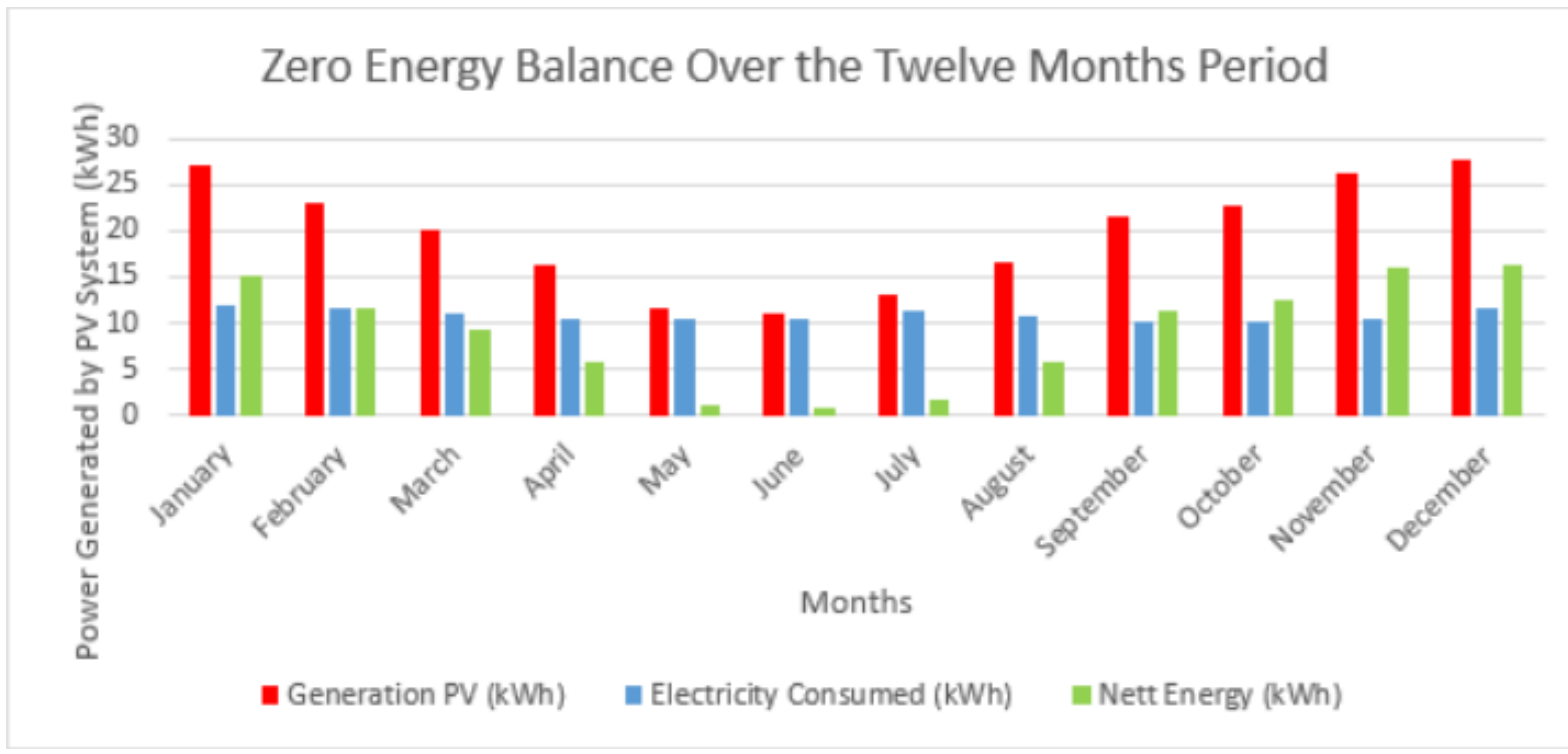

Figure 7: Zero energy balance of each month [2]

In addition, the financial feasibility was analyzed indicating at the possible cost and payback period. It was found that the construction cost of zero energy house would mean $8.9 \%$ more, and that the payback period would last for approximately 10 years [2].

\section{Conclusion}

Environmental sustainability and energy consumption issues are the major concerns worldwide. Scientists and researchers work constantly on finding ways to improve the energy conservation. This research paper aimed to investigate and interpret the secondary data and findings on zero energy houses since it seems that those houses are the best solution for the reduction in energy consumption. Several key trends, barriers and issues were discussed throughout the paper to make the concept clearer. Two different studies were analyzed. First study intended to build a model towards energy neutral or net zero energy house in sub-zero temperature areas. Seven distinct locations with different climate conditions were taken into consideration to simulate the design of zero energy house. In order to generate the solar and wind energy, the on-site renewable resources were used. This study used TRNSYS software. The findings showed that there is a good likelihood towards the installation of zero energy houses supported by the renewable resources.

The second study aimed to design a zero-energy house in Brisbane, Australia to measure its energy performance and financial feasibility. The computer simulation program was used to investigate the potential energy savings through the application of solar energy and other energy efficient equipment. Furthermore, the 
financial feasibility of such house was analyzed by calculating the approximate additional cost and payback period. Although the results showed that there would be additional cost and that payback period would last 10 years, the construction of zero energy house has been shown to be really attractive and feasible option in Brisbane. Zero energy house is a really interesting concept that should be investigated even more in the future since it obviously promises positive changes regarding the energy conservation. Also, zero energy house has many impacts on the field of building physics as indicated throughout the paper. Thermal comfort, HVAC systems, lighting are only some of the aspects deeply studied while designing zero energy house.

\section{References}

[1] J. A. Marszal and H. Per, "A literature review of Zero Energy Building (ZEB) definitions," Aalborg University, Aalborg, 2009.

[2] Y. Kwan and L. Guan, "Design a Zero Energy House in Brisbane, Australia," in 9th International Symposium on Heating, Ventilation and Air Conditioning and the 3rd International Conference on Building Energy and Environment, Brisbane, 2015.

[3] M. Brostrom and G. Howell, "The Challages of Designing and Building a Net Zero Energy Home in a Cold High-Latitude Climate," in International Solar Cities Congress, Adelaide, 2008.

[4] S. Zhang, Z. Zhuang, Y. Hu, B. Yang and H. Tan, "Applicability Study on a Hybrid Renewable Energy System for Net-Zero Energy House in Shanghai," in CUE2015-Applied Energy Symposium and Summit 2015: Low carbon cities and urban energy systems, Shanghai, 2016.

[5] D. Mulvaney and P. Robbins, "Zero-energy building," SAGE Publications, Loughborough, 2011.

[6] E. Perlova, M. Platonova, A. Gorshkov and X. Rakova, "Concept Project of Zero Energy Building," in 25th DAAAM International Symposium on Intelligent Manufacturing and Automation, St. Petersburg, 2015.

[7] L. Pomfret and A. Hashemi, "Thermal Comfort in Zero Energy Buildings," in 9th International Conference on Sustainability in Energy and Buildings, Chania, Crete, Greece, Brighton, 2017.

[8] D. Serghides, S. Dimitrou, M. Katafygioutu and M. Michaelidou, "Energy Efficent Refurbishment Towards Nearly Zero Energy Houses, for the Mediterranean Region," in 7th International Conference on Sustainability in Energy and Buildings, Limassol, 2015.

[9] R. Whit, "Net-Zero Energy Homes a Growing Trend," Portland Press Herald, Maine, 2014.

[10] M. Isaac, L. Tronca and G. Marijan, "Market Analysis of Trends in the Construction of Residential Highly Energy Performing Buildings," Horizon 2020 European Union Funding for Research and Innovation, 2015.

[11] M. Irfan, N. Abas and M. S. Saleem, "Thermal performance analysis of net zero energy home for sub-zero temperature areas," Elsevier, vol. 12, pp. 789-796, 2018. 